University of Nebraska - Lincoln

DigitalCommons@University of Nebraska - Lincoln

USDA Wildlife Services - Staff Publications

U.S. Department of Agriculture: Animal and Plant Health Inspection Service

$1-1-2021$

\title{
Social media as a window into human-wildlife interactions and zoonotic disease risk: an examination of wild pig hunting videos on YouTube
}

\author{
Hailey E. McLean \\ Warner College of Natural Resources, hailey.mclean@colostate.edu \\ Lauren M. Jaebker \\ Warner College of Natural Resources \\ Aaron M. Anderson \\ USDA APHIS National Wildlife Research Center
}

Tara L. Teel

Warner College of Natural Resources

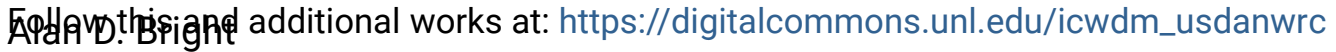

Whert Cqlthge of Natural Resources Conservation Commons, Natural Resources Management and

Policy Commons, Other Environmental Sciences Commons, Other Veterinary Medicine Commons,

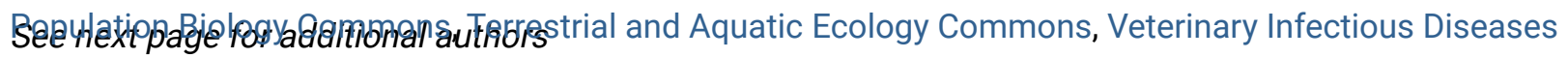

Commons, Veterinary Microbiology and Immunobiology Commons, Veterinary Preventive Medicine,

Epidemiology, and Public Health Commons, and the Zoology Commons

McLean, Hailey E.; Jaebker, Lauren M.; Anderson, Aaron M.; Teel, Tara L.; Bright, Alan D.; Shwiff, Stephanie A.; and Carlisle, Keith M., "Social media as a window into human-wildlife interactions and zoonotic disease risk: an examination of wild pig hunting videos on YouTube" (2021). USDA Wildlife Services - Staff Publications. 2505.

https://digitalcommons.unl.edu/icwdm_usdanwrc/2505

This Article is brought to you for free and open access by the U.S. Department of Agriculture: Animal and Plant Health Inspection Service at DigitalCommons@University of Nebraska - Lincoln. It has been accepted for inclusion in USDA Wildlife Services - Staff Publications by an authorized administrator of DigitalCommons@University of Nebraska - Lincoln. 


\section{Authors}

Hailey E. McLean, Lauren M. Jaebker, Aaron M. Anderson, Tara L. Teel, Alan D. Bright, Stephanie A. Shwiff, and Keith M. Carlisle 


\title{
Social media as a window into human-wildlife interactions and zoonotic disease risk: an examination of wild pig hunting videos on YouTube
}

\author{
Hailey E. McLean (D) ${ }^{\mathrm{a}, \mathrm{b}}$, Lauren M. Jaebker ${ }^{\mathrm{a}, \mathrm{b}}$, Aaron M. Anderson ${ }^{\mathrm{b}}$, Tara L. Teel ${ }^{\mathrm{a}}$, \\ Alan D. Bright ${ }^{a}$, Stephanie A. Shwiff ${ }^{b}$, and Keith M. Carlisle (iD) ${ }^{a, b}$ \\ ${ }^{a}$ Department of Human Dimensions of Natural Resources, Warner College of Natural Resources, Colorado State

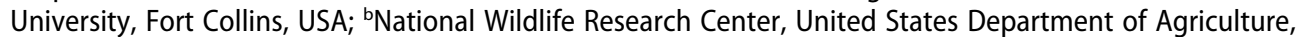 \\ Animal and Plant Health Inspection Service, Wildlife Services, Fort Collins, USA
}

\begin{abstract}
Wild pigs (Sus scrofa) damage agriculture and the environment, as well as transmit diseases to animals and people. Hunters are particularly vulnerable to zoonotic disease risks when harvesting wild pigs. Management agencies have endeavored to inform the public about disease risks associated with wild pigs and best practices for mitigating such risks. However, the extent that this guidance has reached hunters and influenced their practices is unclear. We approached this topic through an analysis of wild pig hunting videos on YouTube. We found evidence of relatively few behaviors and communications regarding disease risks and best practices for personal safety. In contrast, many videos showed behaviors that could increase the risk of disease transmission to the subjects and other animals. We emphasize the importance of understanding the influence of social media on viewers and discuss implications for management agencies, including opportunities for strategic messaging in public health campaigns.
\end{abstract}

\section{KEYWORDS}

Online videos; Sus scrofa; human dimensions; content analysis; mixed methods

\section{Introduction}

Wild pigs (Sus scrofa), whose common names also include wild hogs and feral swine (Keiter et al., 2016), are one of the most problematic species in the world. Experts on invasive species include wild pigs on their list of the 100 "World's Worst" invasive species (Lowe et al., 2000). In the United States, this species causes significant damage to the environment and agriculture, affecting production of row crops, soil composition, water quality, and forest regeneration (Campbell \& Long, 2009). In addition, wild pigs consume and compete with a wide variety of native wildlife and domestic livestock (Seward et al., 2004). Estimated costs of wild pig damage, including control costs, range from 800 USD million (Elsey et al., 2012) to 1.5 USD billion annually in the United States (Pimental, 2007), but are likely much higher given unreported damages, inflation, and the growth of wild pig populations over the past decade.

In addition to the damages they cause, wild pigs also present risks to human health and safety. In recent years, news stories and social media posts have drawn attention to the

CONTACT Hailey E. McLean hailey.mclean@colostate.edu Department of Human Dimensions of Natural Resources, Warner College of Natural Resources, Colorado State University, Fort Collins, USA; National Wildlife Research Center, United States Department of Agriculture, Animal and Plant Health Inspection Service, Wildlife Services, Fort Collins, USA 
potential risks of human injury and death posed by encounters with wild pigs. For example, a man in Arkansas gained national attention in August 2019 when, amid public debates about gun control, he posted a tweet on the social media platform Twitter defending his right to own an automatic rifle to guard against the "30-50 feral hogs" that regularly enter his property and endanger his children's safety (Benwell \& Paul, 2019; Matthews, 2019). The tweet went viral with more than 50,000 retweets and prompted an editorial in The Washington Post about problems associated with wild pigs in rural areas (Horton, 2019). Several months later, an incident involving a woman in Texas who was attacked and killed by a group of wild pigs in a residential neighborhood garnered international news headlines (BBC News, 2019; Bogel-Burroughs, 2019).

Although human injury from wild pigs can and does occur, an arguably greater risk to human health from this species stems from the possibility of disease transmission. With their increasing dispersal, social behaviors, and opportunistic diet, wild pigs are key disease vectors (Brown et al., 2018). Research has shown that wild pigs carry and contribute to the transmission of numerous viruses, bacteria, and parasites that can infect wildlife, domestic livestock, pets, and humans (Bevins et al., 2014). Important zoonotic diseases carried by wild pigs include hepatitis E, tuberculosis, leptospirosis, trichinellosis, and brucellosis (Meng et al., 2009). Numerous severe cases of hepatitis $\mathrm{E}$ have been linked, for example, to the consumption of undercooked meat from wild pigs in Japan (Matsuda et al., 2003; Li et al., 2005; Yazaki et al., 2003). As another illustration, in the United States multiple case reports have documented brucellosis infections in humans following interactions with wild pigs (Brown et al., 2018). Signs of illness were reported in individuals following events of field dressing wild pigs in South Carolina (Starnes et al., 2004), Florida (Carrington et al., 2012), and Georgia (Franco-Paredes et al., 2017).

State and federal agencies, as well as university extension services, have endeavored to inform the public about disease risks associated with wild pigs and best practices for mitigating such risks (e.g., CDC/USDA, 2016; Kinsey, 2020; Mississippii State University Extension, 2020). For example, the Centers for Disease Control and Prevention (CDC) and United States Department of Agriculture (USDA) recommend that people wear appropriate personal protective equipment (e.g., eye protection and disposable gloves) when handling wild pig carcasses, thoroughly wash hands, and properly cook and store harvested meat (CDC/USDA, 2016). The extent that this type of guidance has reached and influenced the practices of those who are at the greatest risk of infection from wild pigs is unclear. Members of the public at greatest risk include hunters who regularly come into contact with wild pigs and their carcasses when handling, field dressing, and butchering the animals following harvest.

With the growing popularity of wild pig hunting and consumption of wild pig meat, the risk of infection is increasing among hunters (Meng et al., 2009). We are unaware of any studies that have examined the extent that hunters adopt practices to avoid infection when harvesting wild pigs. Such research could help public health officials and natural resource managers strategize and prioritize information and outreach efforts to hunters concerning zoonotic disease risks from wild pigs. We approached this topic through an analysis of wild pig hunting videos posted on the social media site YouTube, a popular platform with more than 1.3 billion users and 5 billion videos viewed daily (YouTube, 2020). Our primary research objectives were to understand and describe: (a) the extent that individuals participating in the most influential wild pig hunting videos on YouTube followed any of the 
recommended best practices prescribed by the CDC and the USDA (2016), (b) any communications in these videos or associated video descriptions about disease risks associated with wild pigs and/or practices to mitigate such risks, and (c) any behaviors engaged in by video participants that place them at heightened risk of infection (e.g., handling a carcass without gloves). To contextualize our findings, we also calculated descriptive statistics (e.g., number of views and "likes") for videos and described other video content relating to disease risks (e.g., discussions of cooking or consuming wild pig meat) and other problems associated with wild pigs such as damage to agriculture and risk of injury to humans.

Our rationale for analyzing wild pig hunting videos on YouTube for human behaviors and communications regarding wild pig diseases was two-fold. First, social media sites such as YouTube are a source of rich, and often free, data concerning social processes and conditions (Lopez et al., 2019). Such data can impart a wide array of information on social media users' beliefs, attitudes, and behaviors at specific temporal and spatial scales, as well as across varying contexts (Lopez et al., 2019). Social media data can also be used for understanding how information disseminates among individuals and across networks in addition to unveiling the commonality of public opinion and status of diverse topics (Croitoru et al., 2014). Scholars have proposed that YouTube data can contribute to understanding how nature and the environment, including wild pigs, are framed by everyday people through their interaction and sharing of videos (Mörner \& Olausson, 2017). Importantly, data collected on social media sites may circumvent some of the drawbacks of traditional survey methods, such as misinterpretation of questions (Keeler et al., 2015), social desirability bias, and bias linked with providing pre-determined response options (Murphy et al., 2005). Studies relying on social media data also carry limitations. These limitations include developing meaningful interpretations from such large and dynamic information sources (e.g., meta-data and user-generated content; Stieglitz et al., 2014), as well as reliability and generalizability limitations due to data being incomplete, inconsistent (Boyd \& Crawford, 2012), or skewed in distribution (e.g., reliant on a small number of extremely active users ; Giglietto et al., 2012). Nevertheless, studies utilizing social media data to explore social phenomena can be important and useful complements to survey and other social science research (e.g., ethnographic studies), as evidenced by the growing number of published social media studies in recent years (e.g., Bhavaraju et al., 2019; Chatzigeorgiou \& Christou, 2020; Li et al., 2020).

The second part of our rationale for this research approach stems from our interest in understanding the messaging (even if inadvertent) to viewers, including other hunters, about wild pig hunting and its associated risks. Researchers have found that social media can influence social norms (Romer et al., 2017) and motivate people to act in particular ways (Scherman et al., 2015). For example, multiple studies have shown that social media can influence and shape the behaviors of its users in the realms of politics (DiGrazia et al., 2013), commerce (Kumar et al., 2016), and public health (Korda \& Itani, 2013). In the context of wild pig hunting videos on YouTube, such research implies that some viewers may model their behaviors after others, adopting the practices they observe, such as wearing of gloves and protective eyewear to avoid the risk of infection. The YouTube videos therefore could provide a window into the behaviors and messaging on social media that may influence the practices of wild pig hunters who view the videos. 


\section{Methods}

A mixed-methods approach was taken to collect and analyze quantitative and qualitative data. Such an approach can provide a better understanding of a phenomenon than either method could do independently (Creswell \& Clark, 2007). In our study, combining qualitative approaches (e.g., categorizing video content and assigning sentiment) with quantitative approaches (e.g., counting the occurrences of best practices for personal safety) gave us a richer, more holistic understanding of the nature and frequency of behaviors and communications by influential YouTube videos that bear upon exposure to wild pig disease risks.

\section{Sampling and Data Collection}

Data $^{1}$ for our study were collected from YouTube in July 2019 using an application programming interface (API) obtained from Google. An API describes communications among software intermediaries (Lopez et al., 2019). The API was used to search for relevant videos and extract transcripts, MP4 video files, and associated metadata (i.e., the various pieces of information about a social media post and/or site user). We conducted three searches with differing strings of terms to find videos associated with hunting, field dressing, and butchering of wild pigs in the United States. The three search strings were: "wild hog hunting AND the United States," "wild hog field dressing AND the United States," and "wild hog butchering AND the United States." The term "wild hog" was used because of its popularity within Google search queries in the United States, as determined by Google trends. Similarly, the term "United States" was used within each search string to narrow down the search outputs to the country of interest. The terms "hunting," "field dressing," and "butchering" were used because these are three typical activities a person performs during the hunting process that may involve contact with wild pigs. From each of these three searches, we selected the first 200 videos (amounting to a total of 600 videos), representing the videos that YouTube's search engine deemed most relevant to our inquiries. Given that YouTube's default search optimization sorts videos according to relevance, the videos we selected also represented the first 200 videos a viewer would likely find when conducting the same searches. This helped ensure that the videos we selected were those that reached the largest audiences and could provide the best insight into the content of messaging viewed by YouTube users.

Code provided by YouTube's Data API was compiled and adjusted for use within Python (Version 3.8; Python Software Foundation, 2019), an interpreted, general-purpose programming language. Once in Python, we ran code to extract and export metadata into a Microsoft Excel spreadsheet. We then conducted a review of all 600 videos and any duplicates were removed. Additional metadata collected from YouTube included: video ID, video title, date published, video transcript, video description, video URL, number of views, number of likes, number of dislikes, number of comments, channel ID, channel title, date channel was published, channel description, channel URL, number of total channel views, number of subscribers, and channel country. The API code also enabled us to automatically download most of the videos so that we could view and analyze them at a later time. Videos that were unable to be downloaded via Python code were downloaded using Applian's (Applian Technologies, 2019) high speed streaming downloader software. If a video did not 
have an associated transcript on YouTube, the video was transcribed verbatim, including any visual text that may have appeared in the video. Lastly, we reviewed all YouTubegenerated transcripts for accuracy.

Once we downloaded and saved all videos, transcripts, and corresponding metadata into an Excel spreadsheet, we conducted a systematic review of all videos to identify authentic, hunter-driven videos of wild pig hunting in the United States that met the following criteria: (a) it provided a first-person account of wild pig hunting, (b) all means of communication (either textual or audible) were in English, (c) it took place in the United States, (d) living or dead wild pigs (as opposed to domesticated pigs) were highlighted, and (e) it was free to watch. In addition, any videos posted by state and federal government organizations, news stations, or those that did not show realistic or genuine accounts of wild pig hunting (e.g., docudramas and reenactments) were not included for our final analysis. Authentic, hunterdriven videos were chosen not only because they depict the activities, actions, and operations most relevant to wild pig hunting, but also because personal and relatable posts attract audiences, resulting in more response and engagement (Dekker et al., 2020; Khamis et al., 2016; Raggatt et al., 2018). After all videos were assessed, we retained a final sample of 118 videos for analysis.

\section{Coding and Data Analysis}

The first author viewed and analyzed all videos in the sample, representing 17 hours of video footage. A combined inductive and deductive approach was taken to analyze data from two distinct sources: (a) video footage, and (b) video transcripts/descriptions. Before analysis, categorizations and codes were formulated, corresponding to the best practices prescribed by the CDC and the USDA (2016) and to other themes relevant to disease risks associated with wild pigs. To begin, information from each video's footage was coded for these pre-determined categories. Finally, key themes were identified through deductive coding of transcripts (encompassing in-video audio and visual text), as well as the corresponding video descriptions. Along with this, an iterative process was integrated where the first author continuously revised interpretations and analysis as new insights were gained. Thus, the discovery of relationships and hypothesis generation arose from the analysis of observations (Dye et al., 2000). This approach provided the flexibility to analyze the phenomenon of wild pig hunting via YouTube videos for the presence of predetermined themes and practices while remaining receptive to alternative and contextual considerations and explanations.

Videos were first coded for location. If it was not apparent where the video took place from the video content, title, or description, the item was coded as "unsure." Videos were also coded for the presence of various best practices to mitigate disease risks associated with exposure to wild pigs. The best practices were determined according to guidelines promulgated by the CDC and the USDA (2016) and comprised: (a) wearing eye protection and disposable or rubber gloves; (b) refraining from eating, drinking, or smoking while handling wild pigs; (c) avoiding bare skin contact with animals; (d) not allowing pets to eat raw meat or come into contact with wild pigs; (e) washing hands with soap and water after handling wild pigs; (f) cleaning and disinfecting reusable equipment, tools, and surfaces; (g) keeping raw meat separate from cooked meat and all other foods; and (h) keeping all meat cold (i.e., put on ice or in a cooler). Behaviors that increase exposure and disease risk were also coded, 
including: (a) touching wild pigs with bare hands; (b) not wearing eye protection when handling wild pigs; (c) allowing pets to eat raw meat and/or come into contact with wild pigs; (d) eating, drinking, and/or smoking while handling wild pigs; and (e) storing or placing raw meat with other foods.

We used NVivo (Version 12; QSR International, 2019) qualitative data analysis software to code each video's transcript and corresponding video description. Key themes related to disease risks and best practices that were coded included communications about disease transmission from wild pigs to humans, livestock, pets, and other wildlife. We also coded transcripts and descriptions for communications about wearing personal protective equipment, keeping wild pig meat cold, using sharp knives, cooking meat thoroughly, and communications about intention to cook or eat wild pig meat and sentiment (i.e., view, attitude, or opinion) toward cooking or eating wild pig meat. We also coded communications about other risks associated with wild pigs, including damage to crops, livestock, property, the environment, and wildlife, as well as physical injury to humans and pets.

After the first author generated a list of themes, a second author independently reviewed 18 randomly selected video transcripts and associated descriptions (15\%). We calculated intercoder agreement by taking the total number of times the raters agreed on the presence or absence of a theme, divided by the total number of themes (Neuendorf, 2002). Intercoder agreement before reconciliation was $87 \%$ and $100 \%$ after reconciliation. After the two coders reached agreement on code definitions and interpretation, the first author independently reviewed the codes that were initially assigned to the remaining 100 transcripts/ descriptions and made minor adjustments.

\section{Results}

\section{Video Characteristics and Other Contextual Findings}

There were approximately 75 million views, 500,000 "likes," and 70,000 comments associated with the 118 videos reviewed in our analysis (out of 600). The mean number of views of all sampled videos was $634,916(S D=2,482,881.21 ; M d n=20,746.50)$; the mean number of likes was $4,238(S D=24,561.80 ; M d n=126.50)$; and the mean number of comments was $587(S D=3,135.78 ; M d n=23.50)$. Users who posted the sample videos posted a mean of 587 videos $(S D=1,237.99 ; M d n=164.50)$ to their channel pages and had a mean of 293,522 $(S D=1,070,685.76 ; M d n=12,663)$ subscribers or followers. Of the videos with an identifiable location, $48 \%(n=57)$ took place in Texas, $12 \%(n=14)$ took place in Florida, and the remaining took place in 12 other states. Ninety-five percent $(n=112)$ highlighted some form of hunting where wild pigs were seen being pursued and/or killed and 18\% $(n=21)$ of those videos also highlighted field dressing, butchering, cooking, and/or consumption of harvested wild pigs. Six videos only highlighted field dressing and/or butchering behaviors.

In addition, we found that intent to cook or eat harvested wild pig meat was present in $32 \%$ of videos $(n=38)$. Sentiment toward cooking or eating wild pig meat was present in $26 \%$ of videos $(n=31)$. All 31 of these videos contained subjects who expressed a positive view of consuming harvested wild pig meat (Table 1). In only one video out of the $31 \mathrm{did}$ a subject express negative sentiment toward eating wild pig meat, as follows: "The boars ... they're pretty nasty especially when they get big." However, the subject followed this statement with: "Young hogs are very tasty ...," 
Table 1. Examples of key themes: Intention to cook or eat harvested meat, sentiment toward cooking or eating harvested meat, and communication about other risks.

\begin{tabular}{|c|c|}
\hline Intent to cook or eat harvested wild pig meat & $\begin{array}{l}\text { "So, we should be able to get a lot of piggies for you to come kill them, grill } \\
\text { them, and eat them." } \\
\text { "Well, I say we get this back, and we get it skinned out, cut up, and let } \\
\text { Tommy do some barbecuing on it." }\end{array}$ \\
\hline $\begin{array}{l}\text { Positive sentiment toward cooking or } \\
\text { consuming harvested wild pig meat }\end{array}$ & $\begin{array}{l}\text { "They taste very good. Free pork, can't beat it." } \\
\text { "Take that little bitty guy over there, skinned him out, put some onions } \\
\text { and some peppers, put him in foil, throw him on the smoker, mmm } \\
\text { good stuff right there guys." }\end{array}$ \\
\hline $\begin{array}{l}\text { Communication about damage from wild } \\
\text { pigs }\end{array}$ & $\begin{array}{l}\text { "They tear up food plots." } \\
\text { " ... all of our cow pastures are just demolished from these wild hogs." }\end{array}$ \\
\hline $\begin{array}{l}\text { Communication about potential injury from } \\
\text { wild pigs to people and pets }\end{array}$ & $\begin{array}{l}\text { "I can't believe we found that pig and I can't believe he almost ate us up." } \\
\text { "That thing could have hurt you if it had got you." }\end{array}$ \\
\hline
\end{tabular}

indicating the subject also had a positive view of consuming harvested meat from younger wild pigs. Regarding other risks posed by wild pigs, we found that communication about damage from wild pigs was present in $32 \%$ of videos $(n=38)$. Types of damage communicated by subjects included destruction of crops, personal property, and the environment, as well as competition with and predation on livestock and other wildlife (Table 1). Other risks posed by wild pigs that were communicated by subjects included injury from wild pigs to people and pets (primarily hunting dogs), which was present in $25 \%$ of videos $(n=29)$.

We found that $89 \%$ of videos $(n=105)$ exhibited a commercial intent regarding the content shared within their YouTube video. That is, they were seen as preparing, doing, or acting with sole or chief emphasis on salability, profit, or success of hunting/outfitting services, hunting/firearms equipment, wild pig meat, and/or other wild pig hunting-related products or services. Companies that were mentioned in the video audio and/or visual text included non-hunting related businesses sponsoring production of the video (e.g., DFT Construction), TV shows/channels (e.g., The Sportsman Channel) and media production companies (e.g., Deer Camp Productions), cooking-related companies (e.g., Traeger Grills), outdoor gear companies (e.g., Bass Pro Shops), and hunting-related companies (e.g., Winchester, Bucking Bass Ranch).

\section{Disease Risk and Best Practices}

Analysis of the video footage and video transcripts and descriptions revealed that $27 \%$ of the videos $(n=32)$ contained one or more best practices to mitigate disease risks associated with exposure to wild pigs. Of the 32 videos, all exhibited at least one of the best practices in the video footage (i.e., there was visual evidence that a best practice was being followed; Table 2). In five of these 32 videos, the subjects communicated to viewers about one or more best practices. In particular, the subjects communicated about wearing disposable gloves when handling wild pigs, chilling harvested meat, cooking meat to a high internal temperature, and using sharp knives when field dressing or butchering. However, in none of the videos that showed subjects exhibiting best practices or communicating about them did the subjects state that the purpose of the practice was to avoid disease transmission. In only one video did a subject communicate about the potential for disease transmission from wild pigs (in this case to domestic livestock), but the video was not among the 32 that contained visual evidence of implementing best practices. 
Table 2. Total number of videos (out of 118) in which recommended best practices or behaviors that increase exposure and disease risk were observed.

\begin{tabular}{|c|c|c|}
\hline & & $\begin{array}{l}\text { Total number of videos (out of 118) } \\
\text { in which behaviors were observed }\end{array}$ \\
\hline \multirow[t]{6}{*}{ Recommended practices } & $\begin{array}{l}\text { Keeping raw meat separate from cooked meat and all } \\
\text { other foods when field dressing, butchering, or } \\
\text { cooking }\end{array}$ & 19 \\
\hline & Wearing eye protection when handling wild pigs & 17 \\
\hline & $\begin{array}{l}\text { Wearing disposable or rubber gloves when handling } \\
\text { wild pigs }\end{array}$ & 5 \\
\hline & Keeping all meat cold (i.e., put on ice and/or in a cooler) & 4 \\
\hline & $\begin{array}{l}\text { Washing hands with soap and water after handling wild } \\
\text { pigs }\end{array}$ & 0 \\
\hline & $\begin{array}{l}\text { Cleaning and disinfecting reusable equipment, tools, } \\
\text { and surfaces }\end{array}$ & 0 \\
\hline \multirow{5}{*}{$\begin{array}{l}\text { Behaviors that increase } \\
\text { exposure and disease } \\
\text { risk }\end{array}$} & Touching wild pigs with bare hands & 84 \\
\hline & Not wearing eye protection when handling wild pigs & 72 \\
\hline & $\begin{array}{l}\text { Allowing pets to eat raw meat and/or come into contact } \\
\text { with wild pigs }\end{array}$ & 21 \\
\hline & $\begin{array}{l}\text { Eating, drinking, and/or smoking while handling wild } \\
\text { pigs }\end{array}$ & 3 \\
\hline & Storing or placing raw meat with other foods & 1 \\
\hline
\end{tabular}

In addition, many videos showed behaviors that increased exposure and disease risk to the subjects and to other animals (Table 2). Several of these behaviors were seen among the 32 videos in which subjects also exhibited or discussed one or more best practices. For example, three of the videos revealed subjects consuming food and beverages while handling wild pigs, one video showed a subject putting raw wild pig meat into a cooler with other food, and another showed cats consuming wild pig blood during the butchering process. A subject in one of the videos also communicated that the loin of a harvested wild pig could be eaten raw. Hunting dogs were also seen coming into contact with wild pigs and their carcasses in $8 \%$ of videos $(n=10)$. Lastly, in none of the videos was a subject seen washing their hands or cleaning tools or surfaces when field dressing, butchering, or cooking.

\section{Discussion}

Overall, we found a relatively small number of behaviors and communications regarding disease risks associated with wild pigs and best practices to mitigate such risks in our sample of YouTube videos. In contrast, we found many examples of practices that could actually increase the risk of disease transmission. This sample represented videos that a YouTube user would likely have encountered at the time of our sampling if they searched for content related to hunting or field dressing wild hogs. Although these behaviors and communications could have occurred off camera, viewers may pattern their own behaviors based off of those they view on YouTube, meaning that video creators could be unwittingly contributing to the formation of norms that expose wild pig hunters to greater disease risk. It is conceivable that social media may be the primary source of wild pig hunting information for many of those viewers, and as such, may have a strong influence on their knowledge, attitudes, and behaviors in the realm of wild pig hunting. This argument is supported in part by research showing that an estimated one-half of YouTube users in 2018 (35\% of all adults 
in the United States) used the platform to learn new things and get how-to lessons (Smith et al., 2018). Moreover, multiple studies have shown that social media content can have both negative (Strasburger, 2004) and positive effects (Akram \& Kumar, 2017) on viewers, influencing and shaping social norms (Romer et al., 2017), as well as attitudes (Strasburger, 2004) and behaviors (DiGrazia et al., 2013; Korda \& Itani, 2013; Kumar et al., 2016; Scherman et al., 2015). Although Alessi et al. (2013) hypothesized that the repetitive nature of certain words in hunting videos may influence viewers to repeat what they hear, we hypothesize that some viewers may repeat the behaviors they observe, particularly given the large number of videos in our sample showing behaviors that increased disease risk for the subjects and other animals.

In addition to exhibiting behaviors that could increase disease risk (e.g., touching wild pigs with bare hands), a large portion of the subjects in the videos we analyzed also expressed intentions to cook or eat harvested wild pig meat and positive sentiment toward doing so. This may encourage the preparation and consumption of wild pig meat, which poses disease risks when the meat is improperly handled or not thoroughly cooked (Meng et al., 2009). We found little evidence of explicit communication about such risks and ways to address them. Furthermore, given that the majority of communications about wild pigrelated risks in the videos concerned damage (e.g., destruction of crops, competition with livestock) and injury to people and pets, viewers may be led to conclude that these are the only significant risks posed by wild pigs. Additionally, given the prominence of brand promotion and corporate sponsorship in the videos, the creation and editing of the videos may have been partly motivated and informed by a desire to encourage participation in wild pig hunting and the purchase of associated equipment and services. Communications or behaviors that highlight disease risks associated with the activity could undermine that objective.

Given the need to formulate effective public health campaigns to increase knowledge regarding disease risks associated with wild pigs and best practices to mitigate such risks, social media may provide additional opportunities to effectively communicate messages to the public and hunters. Research has shown that for federal and state agencies that provide public services, the use of social media has considerable capability to connect and interact with the public and specific stakeholder groups (Cockerill, 2013). YouTube, with its 1.3 billion users, is a social media platform that agencies could leverage to reach vast audiences. Furthermore, by considering that many YouTube users who are sharing wild pig hunting videos have experienced significant numbers of views, likes, comments, and subscribers, there may be opportunities for agencies to recruit these users to assist in the creation and distribution of desired messaging. Opinion leaders or influencers are chosen by their peers as individuals who they turn to for expertise and opinions, and may be capable of changing attitudes and behaviors among their peers and followers (Iyengar et al., 2011, Rogers, 2010). There may also be opportunities for agencies to create working relationships with the retailers and companies we identified as major contributors to the content of the wild pig hunting videos. These influencers and companies may benefit from selling protective equipment highlighted as useful in YouTube content that accurately presents disease risks and appropriate responses to these risks.

In capitalizing on these opportunities with social media and creating public health campaigns aimed at hunters, we suggest that the content incorporate best practices for effective messaging (Van Der Linden et al., 2015) by: (a) making messages personal through 
elaboration of hunters' personal experiences and stories hunting wild pigs ; (b) emphasizing current disease risks while making impacts and solutions locally relevant; (c) framing solutions to disease transmission in terms of what could be gained as opposed to lost; (d) appealing to hunters' values and moral foundations; and (e) pairing fear appeals with efficacy appeals (i.e., messages that give the audience the perceived ability to make a difference through one's actions). An example message pairing fear appeal with an efficacy appeal might be, "The wild pigs you hunt can transmit diseases to you and your family. To ensure that you and those around you stay healthy, don't forget to wash your hands after handling wild pigs and cook your harvested meat to an internal temperature of at least $160^{\circ}$ Fahrenheit." More specific to the creation of social media posts, public health campaigns should also consider key factors recommended by Berger and Milkman (2013) that may cause online content to be circulated rapidly and widely, including (a) creating content that excites viewers and makes them feel good or special if they share it; (b) developing a word, phrase, or image associated with a message that reminds viewers of your brand; (c) sharing content that induces an emotional response; (d) posting announcements and current events; and (e) telling stories. In the case of public health information, research has also shown that it is more likely to be shared if it is framed to evoke anger or anxiety rather than sadness (Berger and Milkman, 2013). Public health campaigns aimed at wild pig hunters that, for example, share stories of people getting infected with zoonotic diseases from hunting wild pigs may evoke anxiety and be more likely to be shared.

Moving forward, our findings and study limitations suggest several potentially productive avenues for future research. First, further investigation of wild pig hunting-related videos posted by government agencies, news stations, and other organizational sources not analyzed in this study would provide a useful window into the messaging (intentional or not) that these organizations convey on the YouTube platform. There are also opportunities to further explore the degree that individuals are communicating about disease risks associated with hunting wild pigs and highlighting best practices in content on other media outlets (e.g., television, magazines) and social media platforms (e.g., Instagram, Twitter, Facebook). Additionally, given that social media data have limitations (Boyd \& Crawford, 2012; Giglietto et al., 2012), there is a need for survey research to better understand wild pig hunters' knowledge and perceptions of disease risks and actions taken to mitigate such risks, as well as barriers they face in implementing recommended best practices to limit disease transmission. Integrating findings from social media data and survey research would generate a more complete picture of how the hunting community is responding to the issue of disease risk from wild pigs and how agencies can intervene to improve that response. In addition to spawning ideas for future research, we hope that our study will call attention to the need for raising greater awareness among hunters about the risks of zoonotic disease transmission posed by wild pigs.

\section{Note}

1. Although research on public facing social media content is ruled exempt from human subject review, we did not record or report identifying information about participants to ensure that our study presented no additional risks to them. 


\section{Acknowledgments}

We thank the U.S. Department of Agriculture, Animal and Plant Health Inspection Service, Wildlife Services, National Feral Swine Damage Management Program, and the National Wildlife Research Center for making this research possible. A special thanks to Cheryl Dutro and Jordan Navin for their time and effort helping with data collection and management. Additional support was provided by Colorado State University.

\section{Data availability}

Participants in this study did not agree for their data to be shared publicly, so supporting data are not available.

\section{Disclaimer}

The findings and conclusions in this publication are those of the authors and should not be construed to represent any official U.S. Department of Agriculture or U.S. Government determination or policy.

\section{Disclosure statement}

The authors report no conflicts of interest.

\section{Funding}

This work was supported by the U.S. Department of Agriculture, Animal and Plant Health Inspection Service, Wildlife Services, National Feral Swine Damage Management Program;USDA/APHIS/WS NWRC National Feral Swine Damage Management Program.

\section{ORCID}

Hailey E. McLean (D) http://orcid.org/0000-0002-3892-0334

Keith M. Carlisle (D) http://orcid.org/0000-0002-5205-1294

\section{References}

Akram, W., \& Kumar, R. (2017). A study on positive and negative effects of social media on society. International Journal of Computer Sciences and Engineering, 5(10), 347-354. https://doi.org/10. 26438/ijcse/v5i10.351354

Alessi, M. G., Miller, C. A., \& Harper, E. E. (2013). Content analysis of three waterfowl hunting DVDs. Human Dimensions of Wildlife, 18(2), 152-158. https://doi.org/10.1080/10871209.2013. 745103

Applian Technologies. (2019). Replay capture suite for windows. Applian, LLC. https://applian.com/ windows/

BBC News. (2019, November 26). Woman killed by herd of wild boars outside texas home. https:// www.bbc.com/news/world-us-canada-50564675

Benwell, M., \& Paul, K. (2019, August 5). What about the 30-50 feral hogs? man's defense of assault weapons goes viral. The Guardian. https://www.theguardian.com/us-news/2019/aug/05/feral-hogs -memes-twitter-30-50-running-into-my-yard-small-kids

Berger, J., \& Milkman, K. L. (2013). What makes online content viral?. Journal of Marketing Research,49(2), 192-205. https://doi.org/10.1509/jmr.10.0353 
Bevins, S. N., Pedersen, K., Lutman, M. W., Gidlewski, T., \& Deliberto, T. J. (2014). Consequences associated with the recent range expansion of nonnative feral swine. BioScience, 64(4), 291-299. https://doi.org/10.1093/biosci/biu015

Berger, J., \& Milkman, K. L. (2013). What makes online content viral?. Journal of Marketing Research,49(2), 192-205.https://doi.org/10.1509/jmr.10.0353

Bhavaraju, S. K. T., Beyney, C., \& Nicholson, C. (2019). Quantitative analysis of social media sensitivity to natural disasters. International Journal of Disaster Risk Reduction, 39, 101251. https://doi.org/10.1016/j.ijdrr.2019.101251

Bogel-Burroughs, N. (2019, November 26). Feral hogs attack and kill a woman in Texas. The New York Times. https://www.nytimes.com/2019/11/26/us/texas-woman-killed-feral-hogs.html

Boyd, D., \& Crawford, K. (2012). Critical questions for big data: provocations for a cultural, technological, and scholarly phenomenon. Information, Communication \& Society, 15(5), 662-679. https://doi.org/10.1080/1369118X.2012.678878

Brown, V., Bowen, R., \& Bosco-Lauth, A. (2018). Zoonotic pathogens from feral swine that pose a significant threat to public health. Transboundary and Emerging Diseases, 65(3), 649-659. https:// doi.org/10.1111/tbed.12820

Campbell, T. A., \& Long, D. B. (2009). Feral swine damage and damage management in forested ecosystems. Forest Ecology and Management, 257(12), 2319-2326. https://doi.org/10.1016/j.foreco. 2009.03.036

Carrington, M., Choe, U., Ubillos, S., Stanek, D., Campbell, M., Wansbrough, L., Lee, P., Churchwell, G., Rosas, K., Zaki, S. R., Drew, C., Paddock, C. D., DeLeon-Carnes, M., Guerra, M., Hoffmaster, A. R., Tiller, R. V., \& De, B. K. (2012). Fatal case of brucellosis misdiagnosed in early stages of brucella suis infection in a 46-year-old patient with marfan syndrome. Journal of Clinical Microbiology, 50(6), 2173-2175. https://doi.org/10.1128/JCM.00573-12

Centers for Disease Control and Prevention(CDC)/U.S. Department of Agriculture (USDA).(2016) Wild hog hunting stay healthy on your hunt! [Brochure]. https:/www.cdc.gov/brucellosis/pdf/ brucellosis_and_hoghunters.pdf

Centers for Disease Control and Prevention (CDC)/U.S. Department of Agriculture (USDA). Wild hog hunting stay healthy on your hunt! [Brochure]. https://www.cdc.gov/brucellosis/pdf/ brucel losis_and_hoghunters.pdf(2016).

Chatzigeorgiou, C., \& Christou, E. (2020). Adoption of social media as distribution channels in tourism marketing: A qualitative analysis of consumers' experiences. Journal of Tourism, Heritage \& Services Marketing, 6(1), 25-32. DOI: 10.5281/zenodo.3603355

Cockerill, C. H. (2013). Exploring social media obstacles and opportunities within public agencies: lessons from the ohio division of wildlife. International Journal of Business and Social Science, 4(2), $39-44$.

Creswell, J. W., \& Clark, V. L. P. (2007). Designing and conducting mixed methods research. Sage.

Croitoru, A., Crooks, A., Radzikowski, J., Stefanidis, A., Vatsavai, R. R., \& Wayant, N. (2014). Geoinformatics and social media: New big data challenge. In Big Data (pp. 221-246). CRC Press.

Dekker, R., Van Den Brink, P., \& Meijer, A. (2020). Social media adoption in the police: barriers and strategies. Government Information Quarterly, (2), 101441. https://doi.org/10.1016/j.giq.2019. 101441

DiGrazia, J., McKelvey, K., Bollen, J., \& Rojas, F. (2013). More tweets, more votes: social media as a quantitative indicator of political behavior. PloS One, 8(11), 1-5. https://doi.org/10.1371/journal. pone.0079449

Dye, J. F., Schatz, I. M., Rosenberg, B. A., \& Coleman, S. T. (2000). Constant comparison method: A kaleidoscope of data. The Qualitative Report, 4(1), 1-10.

Elsey, R. M., Mouton, E. C., Jr, \& Kinler, N. (2012). Effects of feral swine (sus scrofa) on alligator (alligator mississippiensis) nests in Louisiana. Southeastern Naturalist, 11(2), 205-218. https://doi. org/10.1656/058.011.0204

Franco-Paredes, C., Chastain, D., Taylor, P., Stocking, S., \& Sellers, B. (2017). Boar hunting and brucellosis caused by brucella suis. Travel Medicine and Infectious Disease, 16, 18-22. https://doi. org/10.1016/j.tmaid.2017.03.006 
Giglietto, F., Rossi, L., \& Bennato, D. (2012). The open laboratory: limits and possibilities of using facebook, twitter, and youTube as a research data source. Journal of Technology in Human Services, 30(3-4), 145-159. https://doi.org/10.1080/15228835.2012.743797

Horton, A. (2019, August 6). Think 30-50 feral hogs is a joke? Millions more are rampaging across the U.Shttps://www.washingtonpost.com/science/2019/08/06/think-feral-hogs-is-joke-millionsmore-are-rampaging-across-us/

Iyengar, R., Van den Bulte, C., \& Valente, T. W. (2011). Opinion leadership and social contagion in new product diffusion. Marketing Science, 30 (2), 195-212

Keeler, B. L., Wood, S. A., Polasky, S., Kling, C., Filstrup, C. T., \& Downing, J. A. (2015). Recreational demand for clean water: evidence from geotagged photographs by visitors to lakes. Frontiers in Ecology and the Environment, 13(2), 76-81. https://doi.org/10.1890/140124

Keiter, D. A., Mayer, J. J., \& Beasley, J. C. (2016). What is in a "common" name? A call for consistent terminology for nonnative. Sus Scrofa. Wildlife Society Bulletin, 40, 384-387. https://doi.org/10. $1002 /$ wsb.649

Khamis, S., Ang, L., \& Welling, R. (2016). Self-branding,'micro-celebrity'and the rise of social media influencers. Celebrity Studies, 8(2), 191-208. https://doi.org/10.1080/19392397.2016.1218292

Kinsey, J. C. (2020). Ecology and management of wild pigs. Texas Parks \& Wildlife. https://tpwd.texas. gov/huntwild/wild/nuisance/feral_hogs/\#disease

Korda, H., \& Itani, Z. (2013). Harnessing social media for health promotion and behavior change. Health Promotion Practice, 14(1), 15-23. https://doi.org/10.1177/1524839911405850

Kumar, A., Bezawada, R., Rishika, R., Janakiraman, R., \& Kannan, P. K. (2016). From social to sale: the effects of firm-generated content in social media on customer behavior. Journal of Marketing, 80(1), 7-25. https://doi.org/10.1509/jm.14.0249

Li, C., Chen, L. J., Chen, X., Zhang, M., Pang, C. P., \& Chen, H. (2020). Retrospective analysis of the possibility of predicting the COVID-19 outbreak from internet searches and social media data, China, 2020. Eurosurveillance, 25(10), 2000199. https://doi.org/10.2807/1560-7917.ES.2020.25.10. 2000199

Li, T. C., Chijiwa, K., Sera, N., Ishibashi, T., Etoh, Y., Shinohara, Y., Kurata, Y., Ishida, M., Sakamoto, S., Takeda, N., \& Miyamura, T. (2005). Hepatitis E virus transmission from wild boar meat. Emerging Infectious Diseases, 11(12), 1958-1960. https://doi.org/10.3201/eid1112. 051041

Lopez, B. E., Magliocca, N. R., \& Crooks, A. T. (2019). Challenges and opportunities of social media data for socio-environmental systems research. Land, 8(7), 1-18. https://doi.org/10.3390/ land 8070107

Lowe, S., Browne, M., Boudjelas, S., \& De Poorter, M. (2000). 100 of the world's worst invasive alien species: A selection from the global invasive species database (Vol. 12). IUCN.

Matsuda, H., Okada, K., Takahashi, K., \& Mishiro, S. (2003). Severe hepatitis E virus infection after ingestion of uncooked liver from a wild boar. The Journal of Infectious Diseases, 188(6), 944. https://doi.org/10.1086/378074

Matthews, D. (2019, August 6). 30 to 50 feral hogs, explained. Vox Media. https://www.vox.com/ future-perfect/2019/8/6/20756162/30-to-50-feral-hogs-meme-assault-weapons-guns-kids

Meng, X., Lindsay, D., \& Sriranganathan, N. (2009). Wild boars as sources for infectious diseases in livestock and humans. Philosophical Transactions of the Royal Society B: Biological Sciences, 364 (1530), 2697-2707. https://doi.org/10.1098/rstb.2009.0086

Mississippii State University Extension. (2020, December 4). Wild pigs and disease. https://www. wildpiginfo.msstate.edu/disease.php

Mörner, C., \& Olausson, U. (2017). Hunting the beast on youTube. Nordicom Review, 38(1), 17-29. https://doi.org/10.1515/nor-2016-0038

Murphy, J. J., Allen, P. G., Stevens, T. H., \& Weatherhead, D. (2005). A meta-analysis of hypothetical bias in stated preference valuation. Environmental and Resource Economics, 30(3), 313-325. https://doi.org/10.1007/s10640-004-3332-z

Neuendorf, K. (2002). The content analysis guidebook. Sage.

NVivo. (2019). NVivo qualitative data analysis software (version 12). QSR International. https:// www.qsrinternational.com/nvivo-qualitative-data-analysis-software/home 
Pimental, D. (2007). Environmental and economic costs of vertebrate species invasions into the United States. Managing Vertebrate Invasive Species, 38, 2-8.

Python. (2019). Python language reference (version 3.8.). Python Software Foundation. http://www. python.org

Raggatt, M., Wright, C. J., Carrotte, E., Jenkinson, R., Mulgrew, K., Prichard, I., \& Lim, M. S. (2018). "I aspire to look and feel healthy like the posts convey": engagement with fitness inspiration on social media and perceptions of its influence on health and wellbeing. BMC Public Health, 18(1), 1002. https://doi.org/10.1186/s12889-018-5930-7

Rogers, E. M. (2010). Diffusion of innovations. Simon and Schuster.

Romer, D., Jamieson, P. E., Jamieson, K. H., Jones, C., \& Sherr, S. (2017). Counteracting the influence of peer smoking on youTube. Journal of Health Communication, 22(4), 337-345. https://doi.org/ 10.1080/10810730.2017.1290164

Scherman, A., Arriagada, A., \& Valenzuela, S. (2015). Student and environmental protests in Chile: the role of social media. Politics, 35(2), 151-171. https://doi.org/10.1111/1467-9256.12072

Seward, N. W., VerCauteren, K. C., Witmer, G. W., \& Engeman, R. M. (2004). Feral swine impacts on agriculture and the environment. Sheep \& Goat Research Journal, 19(12), 34-40.

Smith, A., Toor, S., \& Van Kessel, P. (2018, November 7). Many turn to youTube for children's content, news, how-to lessons. Pew Research Center. https://www.pewresearch.org/internet/2018/ $11 / 07 /$ many-turn-to-youtube-for-childrens-content-news-how-to-lessons/?utm_source= AdaptiveMailer\&utm_medium =email\&utm_campaign=11-6-18\%20Youtube $\% 20$ content\&org= 982\&lvl=100\&ite $=3395 \& l e a=786973 \& \mathrm{ctr}=0 \&$ par $=1 \& \operatorname{trk}=$

Starnes, C., Talwani, R., Horvath, J., Duffus, W., \& Bryan, C. (2004). Brucellosis in two hunt club members in South Carolina. Journal of the South Carolina Medical Association, 100(4), 113-115.

Stieglitz, S., Dang-Xuan, L., Bruns, A., \& Neuberger, C. (2014). Social media analytics. Business \& Information Systems Engineering, 56(2), 101-109.

Strasburger, V. C. (2004). Children, adolescents, and the media. Current Problems in Pediatric and Adolescent Health Care, 34(2), 54-113.

Van Der Linden, S., Maibach, E., \& Leiserowitz, A. (2015). Improving public engagement with climate change: five "best practice" insights from psychological science. Perspectives on Psychological Science, 10(6), 758-763. https://doi.org/10.1177/1745691615598516

Yazaki, Y., Mizuo, H., Takahashi, M., Nishizawa, T., Sasaki, N., Gotanda, Y., \& Okamoto, H. (2003). Sporadic acute or fulminant hepatitis E in Hokkaido, Japan, may be food-borne, as suggested by the presence of hepatitis E virus in pig liver as food. Journal of General Virology, 84(9), 2351-2357. https://doi.org/10.1099/vir.0.19242-0

YouTube. (2020, December 4). YouTube About. https://www.youtube.com/about/ 